Mappemonde

Revue trimestrielle sur l'image géographique et les formes du territoire

$120 \mid 2017$

Varia

\title{
Le maillage communal en Belgique : des héritages différenciés
}

Jean-Baptiste Grison

\section{OpenEdition \\ Journals}

Édition électronique

URL : http://journals.openedition.org/mappemonde/3839

DOI : 10.4000/mappemonde.3839

ISSN : 1769-7298

Éditeur

UMR ESPACE

\section{Référence électronique}

Jean-Baptiste Grison, «Le maillage communal en Belgique : des héritages différenciés », Mappemonde [En ligne], 120 | 2017, mis en ligne le 01 avril 2017, consulté le 15 septembre 2020. URL : http:// journals.openedition.org/mappemonde/3839

Ce document a été généré automatiquement le 15 septembre 2020.

\section{cc) (i) (8) (2)}

La revue Mappemonde est mise à disposition selon les termes de la Licence Creative Commons Attribution - Pas d'Utilisation Commerciale - Partage dans les Mêmes Conditions 4.0 International. 


\title{
Le maillage communal en Belgique : des héritages difFérenciés
}

\author{
Jean-Baptiste Grison
}

1 La Belgique est souvent citée en exemple lorsqu'on parle de réforme de la trame communale. En efFet, elle est parvenue, dans les années 1970, à réduire drastiquement, et presque en une seule fois, le nombre de ses municipalités. Ainsi, la Belgique compte aujourd'hui des communes qui sont, en moyenne, vastes et peuplées. L'hypothèse qui a guidé notre réflexion est que derrière ces moyennes globales, la réforme cache des processus différenciés d'un territoire à l'autre.

2 Dans un premier temps, nous avons comparé les trames municipales d'avant 1970 et d'après 1983, dans le but d'identifier les variabilités respectives de ces deux maillages, avec la question suivante: la réforme a-t-elle permis de corriger les inégalités préexistantes de la trame communale? Il s'avère que le maillage historique était plus dense, en général, au centre qu'en périphérie du pays. En dehors de Bruxelles capitale où aucune fusion n'a eu lieu, on peut considérer que cette opposition a été en bonne partie résorbée : les fusions ont été un peu plus importantes dans les zones où la trame préalable était plus resserrée.

3 Dans un second temps, au-delà des pratiques de la réforme des années 1970, il nous a importé de comprendre le lien entre la trame communale et la répartition des localités, villes et villages, au sein des municipalités. Nous avons pour cela étudié trois arrondissements qui correspondent à des configurations différenciées. Les observations qui en découlent traduisent bien les logiques de convergence observées sur la carte générale.

4 Dans l'arrondissement de Turnhout (province d'Anvers), le nombre de communes a été réduit de moitié seulement ( $52 \%$, contre $80 \%$ pour la moyenne nationale). Trois facteurs concomitants peuvent l'expliquer: les densités de population y sont plus importantes que dans le reste du pays ; la trame des localités y est plus lâche (territoire moins peuplé qu'avant le XIXe siècle, la croissance a eu lieu plus tard) ; par conséquent, les localités sont plus peuplées (les bourgs et petites villes sont plus nombreux que les simples villages). 
5 La comparaison entre les arrondissements de Bastogne (Luxembourg) et Philippeville (Namur) est intéressante, dans la mesure où la trame des localités (villages et bourgs) de l'une et de l'autre est relativement comparable. Pourtant, la trame communale d'avant 1970 était bien plus dense autour de Philippeville, où presque chaque village bénéficiait de l'autonomie politique. Ce n'était pas le cas du côté de Bastogne, où les localités étaient régulièrement regroupées par quatre ou cinq. Dans ce contexte, la réforme a finalement permis un certain rééquilibrage des deux trames, et les contenus des nouvelles communes de chacun des deux arrondissements sont aujourd'hui équivalents.

En conclusion, on peut considérer que la réforme du maillage communal belge a produit un double mouvement, d'une part une relative homogénéisation des maillages ruraux, d'autre part une adaptation à l'évolution des densités de population.

\section{Poster Le maillage communal en Belgique : des héritages différenciés}

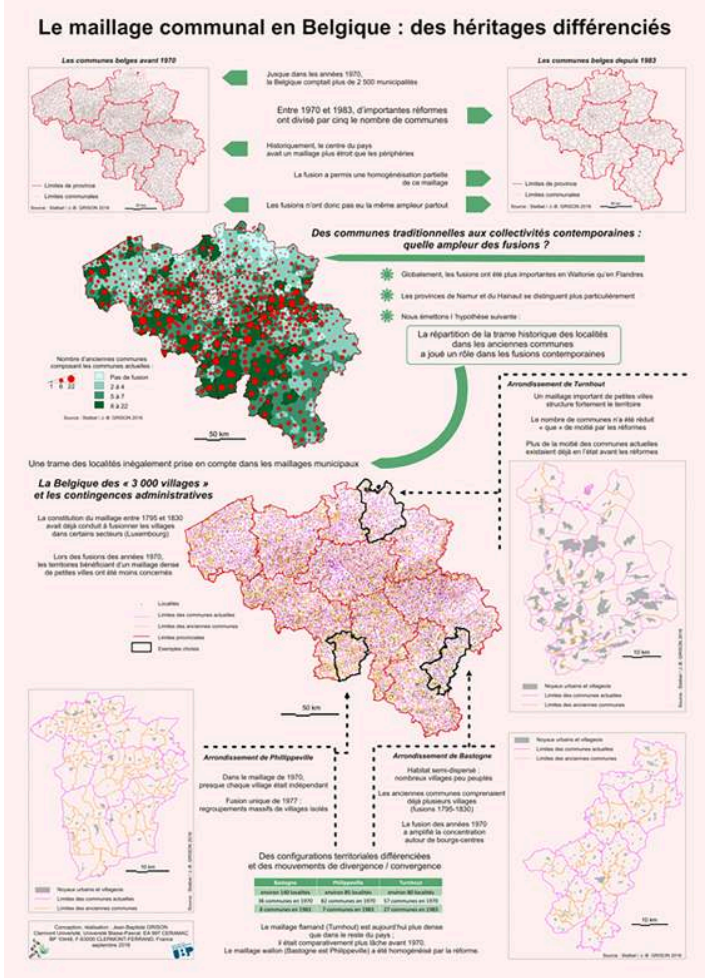

Jean-Baptiste Grison

Télécharger le poster en .pdf ci-dessous.

\section{INDEX}

Mots-clés : FIG, FIG2016 
AUTEUR

JEAN-BAPTISTE GRISON

CERAMAC, Université Clermont Auvergne 